\title{
CONTROVÉRSIAS SOBRE A PROTEÇÃO PATENTÁRIA DE SEGUNDO USO MÉDICO DE COMPOSTOS QUÍMICOS CONHECIDOS
}

\author{
Maria Lucia Abranches da Silva* \\ Escola de Química,Universidade Federeal do Rio de janeiro 21949-909 Rio de Janeiro - RJ, Brasil \\ Adriana Campos Moreira Britto \\ Fundação Oswaldo Cruz, Av. Brasil, 4365 21040-360, Rio de Janeiro - RJ, Brasil \\ Adelaide Maria de Souza Antunes \\ Coordenação de Ensino e Pesquisa em Propriedade Industrial, Diretoria de Articulação, Instituto Nacional de Propriedade Industrial, \\ Praça Mará, 7, 20081-240, Rio de Janeiro - RJ, Brasil
}

Recebido em 17/6/09; aceito em 23/3/10; publicado na web em 20/7/10

\begin{abstract}
CONTROVERSIES ON THE PATENT PROTECTION FOR SECOND MEDICAL USE OF KNOWN CHEMICAL COMPOUNDS. The present work provides an overview of patent protection for second medical use of known chemical compounds, in Brazil and other countries, through the approach of the main controversies related to this theme. That issues encompass aspects related to the legality of the protection granted by the patent, the general requirements of patenteability, the ethic and social concepts and the politic and economic factors involved. This work also introduces the diverging views of the two Brazilian government agencies involved in the procedure for granting patent in the pharmaceutical area, INPI and ANVISA.
\end{abstract}

Keywords: second medical use; patent; new therapeutic applications.

\section{INTRODUÇÃO}

A questão da propriedade industrial no setor farmacêutico é pontuada por discussões polêmicas e controversas, principalmente nos países em desenvolvimento, em que as diferentes visões sobre o tema fomentam tais discussões. De um lado da questão estão as empresas farmacêuticas que alegam que somente através da proteção patentária é possível garantir o retorno dos vultosos investimentos realizados em pesquisa e desenvolvimento (P\&D) e testes clínicos, viabilizando assim a inovação tecnológica. Por outro lado, um dos argumentos utilizados para criticar a proteção por patentes é que esta aumenta o preço dos medicamentos, devido ao monopólio temporário conferido, afetando diretamente o acesso da população aos medicamentos.

Neste cenário, surge a discussão em torno da patenteabilidade de novas aplicações terapêuticas de compostos ou medicamentos já conhecidos, denominadas patentes de "segundo uso médico". Provavelmente mais polêmica que a questão das patentes farmacêuticas em si, a proteção patentetária de segundo uso médico é fortemente criticada. Há quem considere a matéria objeto da patente de segundo uso médico - a nova aplicação terapêutica - uma mera descoberta de uma propriedade intrínseca do composto ou medicamento, e não uma invenção, e, portanto, não seria patenteável. ${ }^{1}$ Consequentemente, a patente de segundo uso médico é muitas vezes vista como uma estratégia das empresas farmacêuticas para prolongar a extensão da proteção de um medicamento já conhecido (evergreening), impedindo a entrada de genéricos no mercado e encarecendo os custos dos sistemas de saúde na compra de medicamentos. ${ }^{2}$

As opiniões contrárias ao patenteamento do segundo uso médico são refletidas nas legislações de patentes de alguns países em desenvolvimento, como os países do Pacto Andino ${ }^{3}$ que incluíram em suas legislações exclusão expressa ao patenteamento desta matéria. Ademais, algumas entidades governamentais e não-governamentais ligadas, principalmente, às questões de acesso à saúde e direitos

\footnotetext{
*e-mail: marialu@inpi.gov.br
}

humanos, tais como instituições públicas de saúde, por exemplo, a ANVISA no Brasil; organizações não-governamentais, por exemplo, o MSF; organizações intergovernamentais, por exemplo, South Centre na América do Sul, também apresentam posição contrária ao patenteamento do segundo uso médico. ${ }^{4}$

Por outro lado, a quase totalidade dos países desenvolvidos, como Estados Unidos, países contratantes da Convenção Europeia de Patentes e Japão, é favorável ao patenteamento do segundo uso médico, fato este que é refletido em suas legislações referentes ao tema. No Brasil, o órgão responsável pela concessão de patentes, o INPI, também apresenta posição favorável sobre o tema. A visão dos que advogam a favor do patenteamento do segundo uso médico é que a restrição à concessão de patentes para esta matéria pode desestimular as pesquisas de novas aplicações terapêuticas, o que de alguma forma também prejudica a sociedade. ${ }^{5}$

Ademais, no caso dos países em desenvolvimento, a pesquisa de novas aplicações terapêuticas a partir de compostos conhecidos está mais ao alcance da indústria farmacêutica nacional, tendo em vista o estágio de desenvolvimento tecnológico. Neste tipo de P\&D, as etapas de pesquisa básica e, muitas vezes, as etapas de testes pré-clínicos e clínicos já foram concluídas durante o desenvolvimento do composto químico para um primeiro uso médico. Assim, no desenvolvimento de um segundo uso médico não há mais necessidade da densidade tecnológica requerida durante a etapa da pesquisa básica, que inclui a síntese do composto químico. Ademais, tendo em vista que muitos destes compostos já passaram pelas etapas de testes pré-clínicos, ou até mesmo testes clínicos, o perfil de reações adversas destes compostos já é conhecido. ${ }^{6}$

Contudo, é importante frisar que o desenvolvimento de uma nova aplicação terapêutica de um composto não pode ser julgada trivial. Apesar de requerer menor densidade tecnológica e menores investimentos em testes clínicos, o desenvolvimento de um segundo uso médico demanda a realização de pesquisas e, no mínimo, a realização de testes clínicos em fase II para a comprovação da eficácia do composto para o novo uso e, inclusive, para atender as exigências das agências reguladoras. No caso de compostos 
químicos que não obtiveram sucesso para a primeira aplicação terapêutica, a situação é um pouco mais complexa. Muitas vezes, é necessária não só realização de testes clínicos, mas também a realização da etapa anterior, isto é, a realização de testes pré-clínicos, a fim de desenvolver e comprovar a nova aplicação terapêutica do composto químico.

\section{A PROPRIEDADE INDUSTRIAL E A INDÚSTRIA FARMACÊUTICA}

A indústria farmacêutica é caracterizada por ser intensiva em pesquisa direcionada para a produção e o acúmulo de novos conhecimentos, com vistas à inovação. O lançamento de produtos novos ou melhorados constitui elemento central no padrão de competição desta indústria, exigindo elevados investimentos em pesquisa e desenvolvimento $(\mathrm{P} \& \mathrm{D})$ e testes clínicos. A indústria farmacêutica conta ainda com respaldo do sistema internacional de propriedade intelectual e expressivos gastos em marketing e propaganda.

Atualmente, estima-se que o investimento em P\&D para cada novo produto seja de US\$800 milhões ou aproximadamente $30 \%$ do custo total do novo produto. ${ }^{7}$ Além de altos investimentos, o desenvolvimento de novos fármacos demanda muito tempo e engloba várias etapas: pré-descoberta - seleção de um alvo farmacológico, relacionado a uma doença que apresente mercado atrativo para o novo medicamento; descoberta - seleção de um grupo de 5.00010.000 compostos candidatos, que apresentem alguma ação no alvo farmacológico selecionado; pré-clinica-emprego de técnicas laboratoriais de experimentação em céluas isoladas e em modelos animais para a avaliação da segurança e biodisponibilidade dos compostos candidatos; clínica - realização de testes em seres humanos para a validação da eficácia e da segurança do composto candidato e para a otimização das doses. A etapa clínica é realizada em 3 fases: fase I - avalia a segurança e tolerância em voluntários saudáveis; fase II - compreende estudos de segurança, eficácia e bioequivalência em pequenos grupos de pacientes e, fase III - inclui testes com diferentes populações para prova de eficácia, segurança e valor do composto; aprovação pela agência reguladora - apresentação de uma coleção extensiva de documentos, incluindo todos os resultados dos estudos pré-clínicos e clínicos e detalhes do plano de produção, para que a agência reguladora aprove ou não a comercialização do medicamento.

Em média, as etapas de descoberta e pré-clínica duram de 3-6 anos e a etapa clínica de 6-7 anos, aproximadamente. No total, o desenvolvimento de um novo medicamento, a partir de um composto químico inédito, dura entre 10 a 15 anos desde a sua descoberta até a comercialização do medicamento final. ${ }^{8}$

Os riscos envolvidos no desenvolvimento de novos princípios ativos também são elevados, de cada 10.000 moléculas sintetizadas somente 5 têm chance de serem comercializadas. Portanto, como o desenvolvimento de uma nova substância ativa demanda tempo, alto custo e risco elevadíssimo, as empresas farmacêuticas devem ter ação internacional para garantir o retorno de seus investimentos. ${ }^{9}$

Neste contexto, a tecnologia resultante dos processos de $\mathrm{P} \& \mathrm{D}$ no setor farmacêutico é protegida por direitos da propriedade intelectual, dos quais patentes e marcas são os mais importantes.

Assim, diferentemente de outros segmentos mercadológicos nos quais parece haver alguma possibilidade de assegurar níveis mínimos de retorno financeiro através de mecanismos alternativos (tais como, know-how e capacidade de produção), no setor farmacêutico a questão patentária assume importância extraordinária desde os estágios mais incipientes de estratégias para o desenvolvimento de novos compostos, em razão do extremo risco dos vultosos investimentos em P\&D. ${ }^{10}$

A patente é um título de propriedade temporária sobre uma invenção ou modelo de utilidade, outorgada pelo Estado ao titular detentor dos direitos sobre a criação. Em contrapartida, o inventor se obriga a revelar detalhadamente todo o conteúdo técnico da matéria protegida pela patente. Durante o prazo de vigência da patente, o titular tem o direito de excluir terceiros, sem sua prévia autorização, de atos relativos à matéria protegida, tais como fabricação, comercialização, importação, uso, venda, etc.

$\mathrm{Na}$ indústria, a patente é tipicamente um instrumento para garantir o retorno dos investimentos realizados, através da comercialização dos produtos patenteados e ainda pelo pagamento de royalties (direitos de propriedade). A exclusividade de exploração conferida ao detentor da patente (monopólio temporário), por um determinado período (dado pelo prazo de validade da patente, de 20 anos, a partir da data do depósito), permite a auferição dos lucros decorrentes do monopólio temporário e, com isso, a recuperação dos elevados custos de P\&D incorridos. Contudo, a patente tem também um objetivo social e desenvolvimentista; visto que, quando uma patente é concedida, em troca de exclusividade, o inventor é obrigado a revelar o conteúdo da matéria protegida pela patente, que poderá servir de fonte de informação tecnológica para estudos e pesquisas realizadas por terceiros, mesmo durante o prazo de vigência da patente. ${ }^{11}$

Deste modo, um sistema de patentes eficaz viabiliza a inovação tecnológica e o desenvolvimento científico, fomenta e incentiva investimentos estrangeiros no mercado interno, é fator preponderante para a produção de riquezas, proporciona a segurança jurídica necessária ao desenvolvimento das relações econômicas e possibilita o relacionamento paritário do país com outras democracias. ${ }^{10}$

A indústria farmacêutica é apontada pela literatura como um dos casos em que a propriedade intelectual é considerada mais relevante para estimular inovações tecnológicas. Essa questão é, contudo, controvertida, e a propriedade intelectual e, em particular, as patentes podem ser consideradas uma barreira institucional à entrada de novas empresas no mercado, assegurando direitos exclusivos e lucros de monopólio da inovação/diferenciação de produto. ${ }^{12}$

Alguns de seus críticos atribuem ao sistema de patentes os altos preços dos medicamentos. Segundo estes, o monopólio de patentes causa grandes distorções econômicas, que no caso de medicamentos provocam aumentos de preços, em média, de 300 a $400 \%$ sobre os praticados no mercado competitivo. ${ }^{13}$

O contra-argumento da indústria é de que as patentes abrangem menos de $2 \%$ dos medicamentos da lista de essenciais da Organização Mundial de Saúde e cobrem apenas 30 a $40 \%$ dos medicamentos éticos (necessitam de prescrição médica para serem vendidos), ao passo que cada produto patenteado enfrenta a competição de 2 a 10 moléculas substitutas próximas destinadas ao mesmo tratamento. A indústria argumenta, ainda, que o prazo efetivo de exploração da patente é inferior ao seu prazo de validade legal, em virtude de haver um longo período de tempo entre o patenteamento do produto e o seu lançamento no mercado, em função dos prazos dos testes exigidos pela regulação. O prazo de efetivo benefício da patente seria, assim, de apenas 6,5 anos. ${ }^{14}$

A proteção por patentes na área farmacêutica pode ser conferida tanto aos produtos mais inovadores, por exemplo, medicamentos que apareceram pela primeira vez no mercado, quanto a outros aspectos do desenvolvimento de um medicamento. Constituem exemplos de desenvolvimento subsequentes de um medicamento, que podem ser protegidos por patentes em escritórios de patentes como o Europeu, dos Estados Unidos e do Japão, esteroisômeros puros, formas cristalinas, métodos de preparação, combinações de dois ou mais ingredientes ativos, excipientes, formas de dosagens, novos usos e, em alguns escritórios como o dos Estados Unidos, até mesmo os métodos de tratamento e diagnóstico podem ser protegidos.

A patente depositada sobre a síntese de um novo princípio ativo é chamada de patente base. É a mais abrangente, pois protege a 
molécula do princípio ativo em si, não podendo ser explorada sem o consentimento de seu titular nos países onde estiver depositada e em vigor, não importando a forma farmacêutica, nem associações, tipos de excipiente, utilização indicada, pois a substância em si fica impedida de exploração. Os desenvolvimentos subsequentes vão sendo patenteados com o tempo, originando um conjunto de patentes, que determina um grau de proibição totalmente variável de fármaco para fármaco e de empresa inovadora para empresa inovadora. Os desenvolvimentos de fármacos geralmente recaem em novas rotas de obtenção ou emprego de intermediários com melhor performance, novos sais farmaceuticamente mais aceitáveis, novas formas cristalinas, novas formas farmacêuticas, associações com outros fármacos, novos métodos de tratamento e novas aplicações. ${ }^{9}$

\section{A PROTEÇÃO PATENTÁRIA DE NOVOS USOS NO SETOR FARMACẾUTICO}

Apesar do crescimento do volume de recursos investido em P\&D e das novas tecnologias disponíveis para o apoio ao processo de descoberta e desenvolvimento de novas drogas, a produtividade da $\mathrm{P} \& \mathrm{D}$ vem caindo na indústria farmacêutica. O ritmo de lançamento de novos medicamentos tem diminuído nos últimos anos, passando de 40 a 50 moléculas inéditas lançadas por ano no mundo na década de 1990 para em torno de 30 moléculas inéditas nos anos 2000. Uma das estratégias adotadas pelas empresas farmacêuticas, para contornar a baixa produtividade em termos de moléculas inéditas, é o investimento em inovações incrementais. O desenvolvimento de novas aplicações terapêuticas para compostos químicos existentes, isto é, o estudo de um possível segundo uso médico de um composto químico, anteriormente desenvolvido para um primeiro uso médico, constitui um exemplo de estratégia de investimento em inovações incrementais adotada pelas empresas farmacêuticas. ${ }^{15}$

Deste modo, assim como empregado para a proteção de outros tipos de invenções na área farmacêutica, o sistema de patentes também é utilizado para a proteção das invenções de novo uso médico.

Em tese, as invenções de novo uso são aquelas relacionadas à aplicação de um objeto já conhecido para a obtenção de um resultado novo e inventivo. Na área farmacêutica, as invenções desta natureza podem ser de dois tipos: primeiro uso médico - uso médico de um composto já conhecido com aplicação fora do campo médico; segundo uso médico - novo uso médico de um composto químicofarmacêutico já conhecido com aplicação no campo médico. Neste contexto, o segundo uso médico pode referir-se a nova aplicação terapêutica tanto para um medicamento já registrado, quanto para um composto químico-farmacêutico em formulação, apresentação e dosagens diferentes daquelas do medicamento registrado. Ademais, o segundo uso médico também pode estar relacionado a uma nova aplicação terapêutica de compostos químico-farmacêuticos que sequer chegaram ao mercado, ou seja, a partir de moléculas que não foram consideradas promissoras para a primeira indicação terapêutica.

Entretanto, as questões envolvidas no patenteamento das invenções de novo uso médico são complexas, tendo em vista que abrangem aspectos ligados à legalidade da proteção conferida pela patente, aos requisitos gerais de patenteabilidade destas invenções, aos conceitos éticos e sociais, e aos fatores políticos e econômicos envolvidos.

Um dos pontos polêmicos sobre o tema refere-se ao fato da patente para um segundo uso médico de um composto químico ser considerada um mecanismo de evergreening adotado pelas empresas farmacêuticas, ou seja, a tentativa de prolongar o monopólio da patente original relacionada ao composto químico propriamente dito. Consequentemente, as patentes de segundo uso médido impediriam a entrada de novos competidores no mercado e o barateamento dos medicamentos.
Neste momento, é importante salientar a distinção entre o mecanismo de evergreening e a inovação incremental. Evergreening pode ser definido como o mecanismo de extensão do monopólio sobre determinado produto patenteado, empregado por algumas empresas farmacêuticas, através da realização de modificações triviais e insignificantes no produto patenteado que são sucessivamente protegidas por meio de múltiplas patentes. Já a inovação incremental também se refere a modificações efetuadas em produtos ou processos já existentes, mas que asseguram maior eficácia aos produtos em termos de efeito terapêutico, menos efeitos colaterais e criação de alternativas de tratamento. ${ }^{16}$

Algumas doutrinas consideram como estratégias de evergreening o patenteamento de novos derivados, isômeros, combinações, formas cristalinas, sais, ésteres, formulações, novos usos, etc. ${ }^{2}$ No entanto, muitos destes aspectos considerados como evergreening são, na realidade, desenvolvimentos subsequentes que adicionam valor ao produto existente e, portanto, representam inovações incrementais. Vale destacar que, muitas vezes, a ação cumulativa de várias inovações incrementais produz mais transformação e mais impacto econômico do que uma inovação radical.

No caso do desenvolvimento de um segundo uso médico, a nova aplicação terapêutica do composto pode conduzir a um potencial terapêutico e comercial sem precedentes e, assim, o desenvolvimento de um segundo uso médico não pode ser considerado trivial ou insignificante. Ressalta-se ainda que a proteção patentária de um segundo uso médico não impede a produção e comercialização por terceiros do composto químico após a expiração da patente original, ou seja, a expiração da patente relativa ao composto químico propriamente dito. O impedimento recai sobre a nova aplicação terapêutica do composto químico, ou seja, o composto químico não pode ser comercializado para a nova aplicação terapêutica.

Com relação à legalidade da proteção das invenções de novo uso médico, o Acordo TRIPs ou ADIPC (Trade Related Aspects of Intellectual Property Rights ou Acordo sobre aspectos dos Direitos da Propriedade Intelectual relacionado ao Comércio $)^{17}$ não fornece indicação sobre este assunto, uma vez que apenas demanda dos países membros da Organização Mundial do Comércio (OMC) ${ }^{18}$ que concedam patentes a produtos e processos em todos os setores tecnológicos. O texto do Acordo TRIPs não especifica qualquer exceção aos novos usos de substâncias já conhecidas, mas também não exige a concessão de tais patentes. Desta forma, o Acordo deixa os países signatários livres para determinar suas próprias abordagens em relação ao patenteamento de novos usos.

Os requisitos gerais de patenteabilidade das invenções foram padronizados pelo Acordo TRIPs, na forma do Artigo 27.1 - “... qualquer invenção, de produto ou de processo, em todo os setores tecnológicos, será patenteável, desde que seja nova, envolva um passo inventivo e seja passível de aplicação industrial...”. Assim, para os países membros da OMC, uma matéria objeto de proteção deve atender aos requisitos de patenteabilidade estabelecidos em TRIPs: novidade, atividade inventiva e aplicação industrial.

Em um pedido de patente, a avaliação destes requisitos de patenteabilidade de determinada matéria deve ser baseada no conteúdo das reivindicações, que traçam o escopo jurídico da exclusividade. Neste contexto, a redação dada às reivindicações é de extrema importância para a determinação dos limites dos direitos do titular assegurados pela patente.

No caso das invenções de segundo uso médico, os requisitos de patenteabilidade também devem ser observados tendo como base as reivindicações contidas no pedido de patente. Contudo, reivindicações direcionadas a nova aplicação terapêutica - "Uso do composto X para o tratamento da doença $Y$ " - são consideradas, na maioria das doutrinas, equivalentes às reivindicações de método de 
tratamento do corpo humano, que são excluídos de patenteamento em aproximadamente 80 países em todo o mundo. Tal fato é previsto no Artigo 27.3 de TRIPS, que estabeleceu que os países membros do Acordo podem considerar como não-patenteáveis os métodos de diagnóstico, terapêuticos e cirúrgicos para o tratamento de seres humanos ou de animais. Assim, a exclusão desta matéria foi facultada a cada país signatário.

No início dos anos 80, o Escritório de Patentes da Suíça contornou o problema relacionado às reivindicações de novo uso, propondo como solução a seguinte redação: "Uso do composto X na preparação de um medicamento para o tratamento da doença $Y$ ", denominada reivindicação de "forma suíça". ${ }^{19}$

Segundo os proponentes da "forma suíça", as referidas reivindicações satisfazem os requisitos de novidade, atividade inventiva e aplicação industrial em duas partes da reivindicação: a primeira, relacionada a "um processo industrial para a preparação de um medicamento usando o composto X", proporciona a devida aplicação industrial; e a segunda parte, relacionada ao "tratamento da doença Y", provê a novidade e atividade inventiva à matéria objeto de proteção. ${ }^{20}$

Entretanto, existem opiniões contrárias à concessão de proteção às invenções de novo uso médico. Os oponentes argumentam que o patenteamento de novos usos médicos, através das reivindicações de "forma suíça", expande o escopo de proteção de forma inconsistente em relação ao requisito novidade, visto que tais reivindicações conferem proteção para o uso do composto para a preparação de um medicamento que normalmente será o mesmo empregado para a primeira indicação terapêutica. Adicionalmente à falta de novidade, outra objeção levantada contra o patenteamento de novos usos médicos está relacionada a não aplicabilidade industrial, uma vez que o elemento novo é um efeito identificado e não um produto ou um método de preparação. ${ }^{21}$

Não há outra doutrina internacionalmente aceita a respeito da proteção por patentes das invenções de novo uso médico. Alguns países - por exemplo, Estados Unidos e países da Comunidade Europeia - decidiram conceder patentes para novos usos como patentes de produto, de processo e/ou uso. Outros países - por exemplo, Argentina - decidiram negar a patenteabilidade de novos usos por falta de novidade, inventividade ou aplicabilidade industrial, ou porque tal uso pode equivaler a um método de tratamento médico (o que pode ser excluído de patenteabilidade sob as ordens do TRIPS), ou porque novos usos são apenas descobertas relacionadas a um produto conhecido e, portanto, não são invenções reais.

Nos Estados Unidos, o Código de patentes vigente, "United States Code Title 35 - Patent", ${ }^{22}$ admite o patenteamento de novos usos de produtos já conhecidos em qualquer área do conhecimento. A Seção 101 deste Código estabelece um amplo escopo de matéria patenteável, incluindo qualquer processo, máquina, manufatura e composição, contanto que seja novo, útil e atenda às demais condições e requisitos estabelecidos no Código. Em relação ao termo "processo", a Seção 100 (b) do Código determina que este significa qualquer processo, arte, ou método, e inclui também um novo uso de um processo, máquina, manufatura, composição ou matéria. Assim, as invenções de novo uso médico são plenamente aceitas pelo Escritório de Marcas e Patentes dos Estados Unidos (United States Patent and Trademark Office (USPTO)). ${ }^{23}$

A este respeito, o Manual de Procedimento de Exame de Patentes (Manual of Patent Examining Procedure (MPEP)) ${ }^{24}$ do USPTO define que usos novos e não óbvios de estruturas e composições já conhecidas podem ser patenteáveis, desde que a descoberta deste novo uso seja baseada em propriedades desconhecidas da estrutura ou composição. Assim, no entendimento do USPTO o novo uso de um composto na área farmacêutica deve ser tratado como os novos usos nas demais áreas tecnológicas, sendo passível de proteção desde que seja novo e inventivo.
Além de conceder proteção às invenções de novo uso médico, os Estados Unidos ainda permitem o patenteamento de métodos terapêuticos. O entendimento do órgão competente (USPTO) é que um método terapêutico equivale a um processo (Seção 100 (b) do Código) e, portanto, é patenteável desde que seja novo, não óbvio e útil, e satisfaça todas as demais condições impostas no código de patentes do país (Seção 101 do Código). ${ }^{24}$

Diferente dos Estados Unidos, os países contratantes da Convenção Europeia de Patentes $(\mathrm{EPC})^{25}$ não concedem proteção aos métodos de tratamento do corpo humano ou animal. O Escritório de Patentes Europeu (European Patent Office - EPO) nega a concessão do privilégio para a matéria com base no Artigo 53(c) da EPC, que enuncia como exceção à patenteabilidade os “...(c) Métodos para tratamento do corpo humano ou animal por cirurgia ou terapia e métodos de diagnóstico praticados no corpo humano ou animal". Por outro lado, neste mesmo Artigo 53(c) da EPC fica claro que "esta provisão não se aplica a produtos, em particular, substâncias ou composições, para o uso em quaisquer destes métodos." Assim, o Artigo 53(c) da EPC distingue claramente entre a não patenteabilidade dos métodos de tratamento e a possível patenteabilidade dos produtos usados nestes métodos.

A novidade de substâncias e composições, já conhecidas com aplicação fora do campo médico, que apresentam primeiro uso médico já era prevista na edição anterior da EPC e nesta última revisão $\left(13^{\mathrm{a}}\right.$ ed.) continuou sendo contemplada no Artigo 54(4). ${ }^{26}$

Com relação ao segundo uso médico, a última revisão da EPC $\left(13^{\mathrm{a}}\right.$ ed.) incluiu no Artigo 54, relacionado à novidade das invenções, um parágrafo contendo permissão expressa para o patenteamento de segundo uso médico. O Artigo 54(5) ${ }^{27}$ introduzido na EPC deixa claro que substâncias ou composições já previamente empregadas nos métodos mencionados no Artigo 53(c) não serão excluídas de proteção, se forem direcionadas a qualquer outro uso específico em um método mencionado no Artigo 53(c), não compreendido no estado da técnica.

Portanto, o patenteamento de invenções de primeiro e segundo uso médico é permitido pelo Escritório de Patentes Europeu (EPO), desde que a matéria objeto de proteção preencha os requisitos de patenteabilidade determinados na Convenção (Artigo 52(1) EPC). ${ }^{28}$

As Diretrizes de Exame no Escritório de Patentes Europeu (Guidelines for Examination in the European Patent Office, Part $C$, Chapter IV $)^{29}$ norteiam a análise dos pedidos de patente relacionados às invenções de novo uso médico. Estas diretrizes esclarecem que os Artigos 54(4) e 54(5) sustentam uma exceção ao princípio geral de que reivindicações de produto só podem ser obtidas para produtos absolutamente novos. Entretanto, tal fato não significa que estas reivindicações de produto, para primeiro e subsequente usos médicos, não precisem atender todos os demais requisitos de patenteablidade, especialmente, o requisito de atividade inventiva. Estas diretrizes ainda prevêem a proteção das invenções de segundo uso médico, se novas e inventivas, empregando reivindicações do tipo "Uso da substância ou composição X para a preparação de um medicamento para a aplicação terapêutica Z" ("forma suíça") ou "Método de preparação de um medicamento empregado na aplicação terapêtica $Z$, caracterizado pelo fato que a substância X é usada".

No Brasil, a proteção de novos usos não está explicitamente estabelecida na atual Lei de Propriedade Industrial (LPI n ${ }^{\circ}$ 9.279/96). ${ }^{30}$ No entanto, o que se observa é que patentes de novos usos são concedidas em todas as áreas tecnológicas, inclusive na área farmacêutica.

Tal fato decorre da adoção pelo Brasil do sistema genérico de classificação, que implica na possibilidade de patenteamento de toda a matéria que não é expressamente excluída de proteção na LPI 9.279/96, desde que atenda aos requisitos de patenteabilidade estabelecidos no Artigo $8^{\circ}$ da referida LPI. ${ }^{31}$ As matérias expressamente excluídas de proteção, por não serem consideradas invenção ou por 
não serem patenteáveis, estão definidas nos Artigos 10 e 18 da LPI 9.279/96. Nestes Artigos não há qualquer menção sobre a exclusão do patenteamento de novos usos.

Extrapolando para o caso em questão, a redação vigente da LPI 9.279/96 não exclui a proteção de segundo uso na área farmacêutica e, portanto, é considerada matéria passível de proteção pelo Instituto Nacional da Propriedade Industrial (INPI), desde que atenda aos requisitos de patenteabilidade estabelecidos na LPI. Corroborando com esta visão, o INPI publicou em 2002 as "Diretrizes para o exame de pedidos de patente nas áreas de biotecnologia e farmacêutica depositados após 31/12/1994, ${ }^{32}$ contendo no item 2.39 orientações para o exame de pedidos relacionados às invenções de segundo uso médico. Segundo estas diretrizes, as reivindicações direcionadas às invenções de segundo uso médico devem ser do tipo "forma suíça".

Em 2007, o INPI iniciou um ciclo de discussões técnicas, com o intuito de aperfeiçoar e desenvolver novas diretrizes de exames de patentes. O segundo uso médico foi tema de discussão, que culminou na elaboração de uma "Minuta para Diretrizes para o Exame de Pedidos de Patentes na Área de Segundo Uso Médico". ${ }^{33}$

Portanto, o Brasil, através da competência conferida ao INPI, apresenta uma posição favorável ao patenteamento de invenções de segundo uso médico, desde que atendam aos requisitos de patenteabilidade estabelecidos no Artigo $8^{\circ}$ da LPI 9.279/96.

Contudo, o INPI não é o único órgão envolvido na concessão de patentes na área farmacêutica. Desde a promulgação da Lei 10.196/01, que alterou a LPI 9.279/96, todos os pedidos de patentes relativos a produtos e processos farmacêuticos devem ser submetidos, após o exame técnico realizado pelo INPI, à prévia anuência da Agência Nacional de Vigilância Sanitária (ANVISA). A competência atribuída à ANVISA, pelo Artigo 229-C da Lei 10.196/01, ${ }^{34}$ tem sido alvo de discussões, uma vez que este artigo da lei não foi regulamentado, motivo pelo qual não se podem estabelecer os reais limites da anuência prévia da ANVISA. A ANVISA adotou a postura de proceder a um novo exame técnico dos pedidos de patente já previamente analisados pelo INPI, caracterizando claramente um duplo exame técnico dos pedidos de patente. Ressalta-se que nem sempre os órgãos apresentam opiniões convergentes no que tange à análise dos requisitos de patenteabilidade dos pedidos de patente. ${ }^{35}$

Em relação ao segundo uso médico, a ANVISA apresenta posição contrária à adotada pelo INPI, negando a anuência aos pedidos relativos a esta matéria. Sobre este assunto, a ANVISA declarou que "Quanto a pedidos que tenham por reivindicação o "novo uso" de substâncias - $A$ Diretoria Colegiada em reunião realizada dia 26 de novembro de 2003 manifestou-se no seguinte sentido: "A Diretoria Colegiada considerou que o instituto é lesivo à saúde pública, ao desenvolvimento científico e tecnológico do país, podendo dificultar o acesso da população aos medicamentos. Neste sentido, decidiu pela não concessão da anuência prévia a casos de pedidos de patentes de segundo uso.",".36

Neste contexto de divergências entre o INPI e a ANVISA, dois Projetos de Lei, PL no2.511/2007 e PL n $3.995 / 2008,{ }^{37}$ foram propostos junto à Câmara dos Deputados, visando a exclusão do patenteamento de matéria relativa ao segundo uso médico de produtos já conhecidos. Estes Projetos de Lei prevêem alterações nos Artigos 10 e 18 da LPI 9.279/96, de modo a excluir a proteção do segundo uso médico.

O PL n².511/2007, proposto pelo Deputado Fernando Coruja, visa a modificação do Artigo 18 da LPI 9.279/96, através da introdução de um novo inciso, o qual inclui o uso terapêutico no rol de matérias não patenteáveis. Caso o PL n².511/2007 seja aprovado, o Artigo 18 passará a vigorar acrescido do seguinte inciso:

“Art. 18 - Não são patenteáveis:[...]

$I V$ - indicação terapêutica de produtos e processos farmacêuticos."
Em sua justificativa para a proposição do referido Projeto de Lei, o Deputado Fernando Coruja argumenta que o PL n².511/2007 visa sanar uma falha existente na LPI 9.279/96. Segundo ele, a falta de definição clara do que são "métodos terapêuticos", expressamente excluídos de proteção pelo Artigo 10 inciso VIII da LPI 9.279/96, tem levado o INPI a conceder patentes para descobertas de novas indicações terapêuticas. Ainda de acordo com a justificativa do autor, uma indicação terapêutica é um atributo intrínseco do fármaco ou medicamento e a descoberta de sua existência não se configura como novidade tecnológica. Ademais, para o autor, a concessão de patente para a descoberta de uma nova indicação terapêutica é vedada, tendo em vista o disposto no inciso I do Artigo 10 da LPI 9.279/96. ${ }^{38}$

Em 2008, os Deputados Paulo Teixeira e Rosinha propuseram novo Projeto de Lei (PL n³.995/2008), com o intuito de demarcar na LPI 9.279/96 restrições quanto à patenteabilidade do segundo uso e de novas formas de substâncias. Diferente do PL n².511/2007 que prevê a modificação do Artigo 18, a proposição dos Deputados Paulo Teixeira e Rosinha contempla a inclusão de dois novos incisos no Artigo 10 da LPI 9.279/96, a fim de ampliar a lista de matérias que não são consideradas invenção. Especificamente no caso do segundo uso, o PL n ${ }^{\circ} 3.995 / 2008$ sugere a inclusão do inciso XI no Artigo 10 com a seguinte redação:

"Art. 10 - Não se considera invenção nem modelo de uti-
lidade: [...]
XI- modificação de produto ou substância terapêutica objeto
de patente, para o qual foi constatado utilidade ou uso diverso
àquele explorado pelo titular da patente."

Para justificar as modificações propostas no PL no $3.995 / 2008$, os autores alegam que uma patente de segundo uso não pode ser concedida, pois a matéria pleiteada já está compreendida no estado na técnica e, portanto, não atende aos requisitos de patenteabilidade dispostos no Artigo $8^{\circ}$ da LPI 9.279/96. Na visão dos autores, a patente de uso não seria uma patente de invenção, mas sim de método terapêutico, que não é considerado invenção de acordo com o Artigo 10 inciso VIII da LPI 9.279/96.

Caso uma das modificações propostas (PL n ${ }^{\circ} 2.511 / 2007$ e ${ }^{\circ}$ 3.995/2008) para a Lei 9.279/96 entre em vigor, o cenário da proteção de novos usos médicos no Brasil muda substancialmente. As invenções de novo uso médico seriam expressamente excluídas de patenteamento, fato que acarretaria a solução das controvérsias entre os órgãos governamentais (INPI e ANVISA) sobre esta matéria, mas que também poderia inibir os investimentos em pesquisa e desenvolvimento de novas aplicações terapêuticas no âmbito nacional, em contraposição à política de incentivo à inovação adotada pelo Brasil.

O que se observa na realidade é uma radicalização das opiniões. As controvérsias sobre o tema podem ser solucionadas através da análise racional do tema. As invenções de novo usos são patenteáveis, desde que atendam aos requisitos de patenteabilidade. A avaliação criteriosa destes requisitos torna-se fundamental para a determinação da matéria que realmente é passível de patenteamento. Assim, mais importante do que proibir o patenteamento das invenções de segundo uso médico é definir com precisão, através de diretrizes de exame, os parâmetros a serem empregados para a avaliação dos requisitos de patenteabilidade para a matéria em questão. Com a delimitação destes parâmetros é possível evitar a proteção de novos usos médicos julgados triviais.

\section{CONSIDERAÇÕES FINAIS}

A proteção patentária das invenções de segundo uso médico engloba aspectos polêmicos e controversos e, nem sempre, as discus- 
sões sobre este tema são claras e conclusivas. A doutrina assumida por cada país ou região está fortemente associada às questões éticas, sociais, políticas e econômicas relacionadas ao patenteamento desta matéria. Assim, no que tange à proteção das invenções de segundo uso médico, não há um consenso sobre seu patenteamento, cada país ou região tem adotado suas próprias interpretações do ponto de vista da legalidade da proteção conferida e dos requisitos gerais de patenteabilidade, influenciado pelas demais questões relacionadas ao tema.

No Brasil, a questão das patentes de segundo uso médico gera um impasse. Não há um consenso entre o órgão responsável pela concessão de patentes, o INPI, e a agência reguladora, a ANVISA. Neste cenário discordante, dois Projetos de Lei tramitam na Câmara dos Deputados, visando a exclusão da proteção para as patentes de segundo uso médico no país. Assim, o patenteamento no setor farmacêutico, mais especificamente, no campo das invenções de novos usos médico, é objeto de debate social e técnico no Brasil. A necessidade de aprofundar este debate é evidenciada pelas visões extremadas sobre o tema, que vislumbram a solução para a questão somente através da exclusão da proteção por patentes de novos usos médicos. Discutir os limites de concessão de proteção às invenções de novos usos médicos deve ser prioridade para a conquista do equilíbrio entre a promoção da saúde pública e os incentivos à inovação no país.

\section{REFERÊNCIAS E NOTAS}

1. http://www.southcentre.org/index.php?option=com_content\&task=vie w\&lang=es\&id=69, acessada em Março 2009.

2. Whitehead, B.; Jackson, S.; Kempner, R.; J. Intellectual Property Law \& Practice 2008, 3, 226.

3. http://www.comunidadandina.org/normativa/dec/D486.htm, acessada em Março 2009.

4. http://www.agenciaaids.com.br/arquivos/patente_parecer.pdf, acessada em Março 2009.

5. Kunisawa, V. Y. M.; IIP Bulletin 2008, 13, 106.

6. Chong, C. R.; Sullivan J. S.; Nature 2007, 448, 645.

7. Moerman, L.; Laan S. V. D.; Crit. Perspectives on Accounting 2006, 17, 1089.

8. http://www.phrma.org/files/attachments/PhRMA\%202009\%20 Profile\%20FINAL.pdf, acessada em Maio 2009.

9. Oliveira, S. N.; Revista Fármacos \& Medicamentos 2004, 30.

10. Falcone, B; Propriedade Intelectual - Estudos em Homenagem à Professora Maristela Basso, 2a ed., Juruá Editora: Curitiba, 2005.

11. Arora, A.; Research policy 1997, 26, 391.

12. Bastos, V. D.; BNDES Setorial 2005, 22, 271.

13. Baker, D.; 2008 Industry Studies Conference Paper, Boston, Estados Unidos, 2008.

14. http://www.ifpma.org/documents/NR1916/PIP_final.pdf, acessada em Março 2009.

15. Reis, C.; Capanema, L. X. L.; Palmeira, P. L.; Pieroni, J. P.; Barros, J. O.; Silva, L. G.; BNDES Setorial 2009, 29, 359.

16. http://www.who.int/entity/intellectualproperty/submissions/ Pharmacoevolution.pdf, acessada em Dezembro 2009.

17. TRIPS ou ADIPC (Trade Related Aspects of Intellectual Property Rights ou Acordo sobre aspectos dos Direitos da Propriedade Intelectual relacionado ao Comércio): trata dos direitos de autor e conexos, marcas, indicações geográficas, desenhos industriais, patentes, topografias de circuitos integrados, proteção do segredo de negócio e controle da concorrência desleal. Estabelece princípios básicos, quanto à existência, abrangência e exercício dos direitos de propriedade intelectual.
18. OMC ou WTO (Organização Mundial do Comércio ou World Trade Organization): organismo multilateral, internacional, para construção, defesa e desenvolvimento do sistema mundial do comércio. Foi criada pelo Acordo de Marraqueche, em 15/4/1994, entrando em vigor em 1\%1/1995.

19. htt p://pharmalicensing.com/public/articles/view/ 977438120_3a4285a8a07d8/, acessada em Dezembro 2008.

20. http://www.wptn.com/wptn/IssuePages.aspx?htmlpath=pat_015_jul01. htm\&issuedate $=31 \% 20 \mathrm{Jul} \% 202001 \&$ topic $=$ Patents $\% 20$ and $\% 20$ Designs, acessada em Dezembro 2008.

21. Correa, C. M.; Int. J. Intellectual Property Management 2006, 1, 4.

22. United States Code Title 35 - Patents (Rev. 6): legislação de patentes vigente nos EUA; http://www.uspto.gov/web/offices/pac/mpep/ consolidated_laws.pdf, acessada em Dezembro 2008.

23. USPTO - "United States Patent and Trademark Office ou Escritório de Marcas e Patentes dos Estados Unidos": Agência Federal Americana responsável pelo exame e concessão de patentes, e exame e registro de marcas.

24. http://www.uspto.gov/web/offices/pac/mpep/mpep.htm, acessada em Dezembro 2008.

25. EPC - "European Patent Convention" (13 a Ed.): Convenção Europeia de Patentes que viabilizou a implantação da patente europeia unificada (regional) nos países contratantes; http://www.epo.org/patents/law/legaltexts/epc.html, acessada em Dezembro 2008.

26. Artigo 54(4) EPC (13ª ed.): "Parágrafos 2 e 3 não excluem a patenteabilidade de qualquer substância ou composição, compreendida no estado da arte, para uso em um método mencionado no Artigo 53(c), contanto que este uso para qualquer tal método não está compreendido no estado da arte."

27. Artigo 54(5) EPC (13 ed.): "Parágrafos 2 e 3 também não excluem a patenteabilidade de qualquer substância ou composição mencionada no parágrafo 4 para qualquer uso específico em um método mencionado no Artigo 53(c), contanto que este uso não está compreendido no estado da arte."

28. Artigo 52(1) EPC (13 a ed.): "Patentes européias podem ser concedidas para quaisquer invenções, em todos os campos da tecnologia, desde que sejam novas, envolvam um passo inventivo e sejam suscetíveis de aplicação industrial."

29. http://www.epo.org/patents/law/legal-texts/guidelines.html, acessada em Dezembro 2008.

30. http://www.inpi.gov.br/menu-esquerdo/patente/pasta_legislacao/ Lei9279.pdf, acessada em Dezembro 2008.

31. Artigo $8^{\circ}$ da LPI 9.279/96: "É patenteável a invenção que atenda aos requisitos de novidade, atividade inventiva e aplicação industrial."

32. http://www.inpi.gov.br/menu-esquerdo/patente/pasta_manual, acessada em Dezembro 2008.

33. http://www.inpi.gov.br/menu-esquerdo/patente/discussoes-tecnicas/ diretrizes-para-o-exame-de-pedidos-de-patentes-na-area-de-segundouso-medico, acessada em Março 2009.

34. Artigo 229-C da Lei no 10.196 que alterou a LPI 9.279/96: “A concessão de patentes para produtos e processos farmacêuticos dependerá da prévia anuência da Agência Nacional de Vigilância Sanitária ANVISA.".

35. Wolff, M. T.; Antunes, P. B.; Revista da ABPI 2005, 74, 48.

36. http://www.anvisa.gov.br/divulga/informes/2004/ 250804.htm, acessada em Dezembro 2008.

37. http://www2.camara.gov.br/proposicoes, acessada em Abril 2009.

38. Artigo 10-I da LPI 9.279/96: “Não se considera invenção nem modelo de utilidade: I - descobertas, teorias científicas e métodos matemáticos;" 